\title{
A Comparative Study of Sense of Presence of Traditional Virtual Reality and Immersive Environments
}

\author{
Max M. North \\ Visualization \& Simulation Research Center \\ Information Systems Department-Coles College of Business \\ Computer Science Department-College of Computing and Software Engineering \\ Kennesaw State University, Kennesaw, GA 30144, USA \\ max@kennesaw.edu \\ Sarah North \\ Visualization \& Simulation Research Center \\ Information Systems Department-Coles College of Business \\ Computer Science Department-College of Computing and Software Engineering \\ Kennesaw State University, Kennesaw, GA 30144, USA \\ snorth@kennesaw.edu
}

\begin{abstract}
User experience is a critical component in the development of virtual environment systems and applications. To create an effective and efficient user experience for virtual environment systems, it is imperative to conduct empirical studies to explore factors that contribute to a heightened sense of presence, or immersion, for users, who increasingly demand an experience in a virtual environment that seems as real as possible. The primary hypothesis of this study is that participants will experience higher levels of presence in an Immersive Visualization Environment (IVE) than in a Traditional Virtual Reality Environment (TVRE). The empirical methodology consists of two different experiments designed, developed, and implemented using seventy participants. A simulated virtual airplane scenario was created and conducted for each participant. After completion of each simulation session, each participant was given a questionnaire that measured the participant's sense of presence in either virtual or real environments. Analysis of the collected data indicated that there was a statistically significant difference in the level of presence experienced by participants between the TVRE and IVE systems. The primary conclusion is that participants experienced a higher sense of presence in the IVE experiment when compared with the TVRE experiment, indicating significantly more natural and richer user experience through the IVE system's interface.
\end{abstract}

Keywords: Sense of presence; Immersive environments; Virtual reality

\section{Introduction}

Over the last few decades, the importance of user experience in virtual environment systems has become paramount, and this element is recognized as a critical component of the design and development of these systems. Consequently, there is an increased need to conduct empirical studies to explore factors that create a higher sense of presence, or immersion, for users. The main goal is to ultimately develop a scientific body of knowledge and a framework to assist researchers in the development of future virtual environment systems and applications that provide real and natural interface and user experiences.

There are different aspects that make virtual reality feel as real as possible to users. One wellknown aspect of virtual reality is a sense of presence in the virtual environment. It is often thought of as the sense of "being there." In the 1990s, a few theoretical articles exploring virtual presence were published in the journal of Presence: Teleoperators and Virtual Environments, published by the Massachusetts Institute of Technology, MIT (Pausch, Proffitt \& Williams, 1997; Sheridan, 2000; Hendrix \& Barfield, 1995; Slater, Usoh and Steed, 1994; Slater, 1999; Witmer \& Singer, 1998; Zeltzer, 1992). Since that time, more and more researchers have been harvesting the power of presence, which in turn has contributed new knowledge to extend a 
deeper understanding of different the causes and nature of this sense of presence; these studies include Post-traumatic Stress Disorder Treatment (Hodges et al., 1999; Rizzo et al., 2010), Virtual Reality Therapy (North, North \& Coble, 1996a), Fear of Flight Phobia Treatment (North, North \& Coble, 1996b), Arachnophobia Treatment (Bouchard, 2006), Treatment for Burn Pain (Hoffman et al., 2000; Palyo, Schopmeyer \& McQuaid, 2010), and VR Based Therapy for the Treatment for Impotence and Premature Ejaculation (Optale et al., 1998); Influence of Personality on the Sense of Presence Experienced in Anxiety Triggering Virtual Environments (Jurnet \& Maldonado, 2010); Measuring Sense of Presence and User Characteristics to Predict Effective Training in an Online Simulated Virtual Environment (De Leo et al., 2014); Beyond Presence: How Holistic Experience Drives Training and Education (Chertoff \& Schatz, 2014).

Although development of research has progressed through the years, our understanding of the theoretical aspects of presence remains limited, and more experimentation is needed in this area. We reiterate from our earlier research in the field along with many pioneers here: There is a great need to develop a scientific body of knowledge and a framework to assist researchers in the development of efficient and effective virtual environment applications, and within this framework to rigorously investigate the sense of presence. This current research has been designed and implemented to explore the sense of presence and its relationship in real and virtual environments. To do so, authors focus on investigating sense of presence comparing two different virtual environments: Traditional Virtual Reality Environment (Helmet-based system with a Head-tracking device) an innovative virtual reality environment using an Immersive Environment (Spherical-based virtual environment).

\subsection{Sense of Presence}

How is "presence" defined? In 1980, Marvin Minsky coined the term "telepresence" and described telepresence as "refer[ing] to the phenomenon that a human operator develops a sense of being physically present at a remote location through interaction with the system's human interface" (Coelho et al., 2006, p. 2). Over time, the study of "telepresence" yielded to the general study of "presence," since telepresence is more commonly used with teleoperations. Over time, many articles and journals defined presence differently, but all had a similar general meaning. In this research paper, the main definition of presence that will be used is the awareness or state of the mind of being in an environment, either real or virtual (Usoh et al., 1999; Nunez \& Blake, 2001). Experiencing a sense of presence can happen whenever a person mentally feels that he or she is present in a situation. For example, when reading a book, some people may feel what the characters are feeling, and they become wrapped up in the bookthey may feel as though they are watching a movie or have an even deeper connection with the text. The traditional way of thinking of presence stems from the writings of René Descartes and the German philosopher Immanuel Kant. They made a clear distinction between objects located in the mind and objects located outside of the mind (Sheridan, 1999). One of the first theoretical articles on presence described it as the feeling of "realness, vividness, and feeling very much alive" (Fontaine, 1992, p.41). There was also a proposed division of the definition of presence, separating it into subjective presence (a conscious state-of-mind) and behavioral presence (an unconscious state-of-mind) (Slater, 2002; Slater, 2009).

A more recent definition of presence is "how realistically participants respond to the environment as well as their subjective sense of being in the place depicted by the Virtual Environment" (Yu et al., 2012, p.76). Yet other researchers, Sanchez-Vives \& Slater, (2005) define the concept of presence as a phenomenon of behaving and feeling as if participants are in the virtual world created by computer displays. In their article, they argue that study of presence is essential to neuroscientists, that in turn it might aid the study of perception and consciousness. As an example of the power of this phenomenon, Juan et al. (2006) show how the sense of presence played a dominant role in an augmented reality system for the treatment of acrophobia using immersive photography. Most participants in this study showed a higher subjective sense of presence with immersive photography. 
While there are a good number of applied researches in virtual environment field that directly utilize sense of presence and ultimately contribute to the comprehension of this phenomenon, there seems to be a shortfall of in-depth studies into the pure theoretical aspect of sense of presence. In addition, because of the complex nature of the sense of presence, past investigations have been very focused and limited to specific studies, leaving unanswered questions. This study expands on some of those unanswered questions: What is presence exactly? Does presence go beyond the physical attributes and into the cognitive mind? What is virtual reality, and how does a person's sense of presence change in the virtual environment? What factors contribute to the sense of presence in an environment, either virtual or real? What is the best method or device used for measuring presence? Therefore, one of the main goals of current and future research is to study the sense of presence by proposing a series of testable propositions and by using significant experimentations to build theories that in turn will assist future researchers and application developers.

\subsection{Factors Affecting Presence}

There are many factors that contribute to one's sense of presence. One classic study in particular from Sheridan at MIT summarizes and gives some additional enlightenment on these factors. Sheridan proposes that there are four major variables that affect a person's immersion in an environment. The first is the quantity of information that gets through to the participant. This depends on whether the participant is paying attention and on the level of visual or auditory distractions in the environment. The second variable is sensor position and orientation, which in the context of head-tracking devices deals with the degree of corresponding visual feedback. The third is the change of relative location of objects in response to static feedback (such as gravity) and direct manipulation commands (Sheridan, 1999). For example, a study by Usoh et al. (1999) indicated that naïve subjects in an immersive virtual environment experience a higher subjective sense of presence when they move by walking in place than when they "push-button fly." The fourth variable to be considered is an active imagination in suppressing disbelief. This factor is the most difficult to control and generally relies on a large enough participant base to even out differences.

Steuer (1992) proposed three different factors involved with a person's presence in virtual reality. Those factors are vividness, interactivity, and the influence of the user's characteristics. Vividness is the representational richness of a mediated environment defined by its formal features. Interactivity can be defined as the extent to which users can participate in modifying the form and content of a mediated environment in real time. Getting a person more engaged in what is being seen can have a major effect on how a person perceives the virtual world. The final factor Steur talks about is the influence of a user's characteristics. This derives from the individual differences in the sense of presence when subjects are confronted with the same virtual environments. The individual's personal experiences contribute to this factor.

Because there was no direct manipulation in the airplane simulation, Steur's second factor, interactivity, was not used in either experiment. However, care was taken to keep a standard across participants so that the other variables introduced above, especially auditory and visual distractions, as well as the head-tracking device, were constants for the data sample. Sheridan focused predominately on environmental factors, while another study focusing on therapy through virtual reality focused much more on the psychological factors affecting immersion. Psotka and Davison found that "immersion was most affected by how claustrophobic one is. The more claustrophobic you are the more often you think about the other person(s) in the real world with you there. How immersed one feels appears to be determined by a complex set of physical components and affordances of the environment, as well as psychological processes that as yet are poorly understood" (Psotka \& Davison, 1993, p.71). This study did not take into account any atypical psychological issues, but rather relied on averaging to represent the majority. This complex set of factors, both environmental and psychological, is what makes typical subjective measures of presence challenging. Because this study was measuring sense 
of presence and not these variables themselves, as long as the variables were turned into constants as much as possible, the data sample was considered representative of the average.

According to J urnet and Maldonado (2010), who investigated the influence of personality and individual abilities on the sense of presence experienced in anxiety-triggering virtual environments, spatial intelligence has an influence on the sense of presence in an immersive virtual reality system. There is also a strong relationship between users' personality characteristics and their sense of presence in a virtual environment. A ten-year critical review of empirical research of educational applications of virtual reality was conducted by Mikropoulos and Natsisl (2011). Researchers reported multisensory interaction channels and visual representation within virtual reality as a dominant factor effecting sense of presence.

\subsection{Measuring Presence}

There has been some discussion on the ways to measure presence. One way to measure presence is to observe how people physically react to stimulation; we can call this behavioral presence(Witmer and Singer, 1998; Zeltzer, 1992; Meehan et al., 2002; Ijsselsteijn et al., 2002; North, 2002; Riva et al., 2007; Lee, Chou \& Sun, 2015). Behavioral presence focused mainly on the movements of the subjects and on spontaneous speech. A study headed by Dillon et al. (2001) out of New Cross London discussed some of the issues that arise when attempting to measure presence. Physiological measures of presence have been proposed to be the most accurate and objective possible measurement. Dillon notes that the "unifying idea behind this approach is that as presence within a displayed environment increases, physiological reaction will tend towards those that would be observed in a real environment. Alternatively, these objective, continuous measures could provide additional information about viewing experiences which are not tapped by post-test subjective rating scales, which may be prone to demand characteristics and memory biases" (Dillon et al., 2001, p.83). However, such measures may not be appropriate in cases when even a high amount of presence does not physically stimulate the subject, such as when a subject moves a chair in a virtual environment. After an in-depth study that compared heart-rate monitoring, skin-conductance monitoring, and survey methods, Dillon concluded that physiological measures are an addition to subjective presence measures, but not a replacement (Dillon et al., 2001). Since this experiment was a simulation of simply being in an airplane, it was determined that physiological measures would not have been a very valuable addition to the subjective measures.

Presence is a subjective condition, and it has most commonly been measured using self-reports by administrating questionnaires either during or immediately after the experiment ( $\mathrm{J}$ uan et al., 2009). To properly measure presence, several questionnaires have been suggested (Barfield et al., 1995; Lombard \&Ditton, 1997; Sheridan, 1996; Slater et al., 1994; Slater, 1999; J une et al., 2009; North et al., 2002; Lin et al., 2002; Lee et al., 2015). Based on the research briefly described above, particularly the questionnaire originally developed by Slater et al. (1994), questionnaires that measured subjective self-reports were administered immediately after the completion of the simulation sessions for both IVE and TVRE experiments.

\section{Empirical Research Methodology}

\subsection{Hypothesis, Objectives, and Terminology Usage}

The primary hypothesis of this research is that participants will experience higher levels of presence in an Immersive Visualization Environment (IVE - a spherical, projected virtual environment) than in a Traditional Virtual Reality Environment (TVRE - a helmet-based system with a head-tracking device). The first objective of this research was to design, configure, develop and implement an innovative IVE. The second objective was to investigate the sense of presence induced in participants by the Immersive Visualization Environment and compare it with the sense of presence felt by participants who experienced the Traditional Virtual Reality Environment. Please note that for improved readability and comprehension, the terminology "Immersive Visualization Environment" and "IVE" will be used 
interchangeably and simultaneously throughout this paper, as will "Traditional Virtual Reality Environment" and "TVRE".

\subsection{Experimental Design Based on Preceding Comparative Studies}

There are two main types of comparisons. The first type is the comparison of extreme opposites, like CAVE (Cave Automatic Virtual Environment, an immersive virtual reality with projectors are pointed to between three and six walls of a room-sized cube) and standard desktop computers (Gruchalla, 2004; Shim \& Kim, 2004; J uan \& Perez, 2009). The second type refers to studies that utilize external factors such as field-of-view, stereoscopy, headtracking, sounds, and augmentation (Hendrix \& Barfield, 1995; Waterworth \& Waterworth, 2003; J uan, Calatrava, 2011; North \&North, 2002; Arino et al., 2014; Lee, Chou \&Sun, 2015). The design of this empirical research methodology is primarily based on this second class of comparisons, incorporating limited features from the first type. We use best practices of the studies mentioned in prior sections.

\subsection{Participants and Site for TVRE and IVE Experiments}

Seventy volunteer college students ranging in age from twenty to forty-eight years old participated in the study. Their mean age was twenty-eight years. They were recruited by advertisements on the university campuses. Participants were counterbalanced and arbitrarily assigned to the following two experiments:

- $\quad$ TVRE experiment: Traditional Virtual Reality Environment (n=35), 23 male and 12 female.

- IVE experiment: Immersive Visualization Environment ( $n=35), 25$ maleand 10 female.

The site of both experiments was Visualization \& Simulation Research Center at Kennesaw State University. TVRE and IVE systems were implemented to work independently, but in the same facility. Each experiment was conducted in a different time frame, so there was no communication or interaction between participants of each experiment until after the research was concluded. This arrangement allowed for monitoring with high validity the collected data through the individually administered questionnaires.

\subsection{Instrument used for TVRE and IVE Experiments}

Presence is a subjective condition most commonly measured using subjective self-reports by administrating questionnaires either during or immediately after the experiment. In both experiments, a streamlined version of the UCL Presence Questionnaire, also termed the Subjective Measure of Presence (SMoP) and originally developed by Slater et al. (1994), was used. This post-experience subjective measure of presence was administered immediately after each simulation for both experiments. Participants were asked to provide ratings on an 11point Likert scale (with 0 being the lowest and 10 being the highest) on two selected questions from the questionnaire - the subjective questions that were directly related to presence and correlated to the hypothesis of this study. The same questions were posed to participants of both experiments:

- Question 1-Rate your sense of presence in the real world while experiencing the virtual world.

- Question 2-Rate your sense of presence in the virtual world during the experiment.

Based on our prior experiences, questions were kept simple in order to allow participants to focus on their responses and report accurate subjective ratings. For this reason, we used "virtual world" term to denote to "TVRE" or "TVE" in each distinct experiment.

All participants were given an explanation of the experiments and instructions about interaction protocols with the environments before actually experiencing the virtual environments. Authors replied to all the participants' questions and secured their signed consent forms for participating in experiments. 


\subsection{Traditional Virtual Reality Environment Experiment (TVRE)}

Apparatus: The virtual reality system for this part of the study consisted of a Pentium-based computer using a 6D head-tracking system and display. The virtual environments were created using the Sense8 ${ }^{\mathrm{TM}}$ Virtual Reality Development Software Package and Libraries. Each session was executed using the Virtual I-O Glasses with a head-tracking device. The VR helmet provided a $360^{\circ}$ field of view, which allows the participants to see the image at any direction they look. The virtual environment scene used was a moderately simple rendition of a windowseat passenger's view of an airplane taking off and flying during bad weather (see Figure 1). This environment was called Traditional Virtual Reality Environment or TVRE.

Procedure: The participants individually were seated in an aircraft-like seat equipped with vibration capabilities which simulated engine vibration and flight turbulence. The participants could partially view their bodies. The subject listened to sounds such as the flight attendant speaking, engine noises, and noises due to turbulence. The only control the participants had over the simulation was through the head-mounted tracking system that responded to their head movements by moving the view in the virtual world. Participants experienced thirty minutes in the airplane simulation before being administered the SMoP sense of presence questionnaire immediately afterward. The definition of presence, given beforehand, was "the sense of being there," where "there" meant the particular environment referenced. Participants rated the questions quantitatively on a scale of 0 to 10 (Likert scale), with zero being equal to no sense of presence and ten being equal to complete immersion in the environment. There were no other rules imposed on how subjects could score their sense of presence.

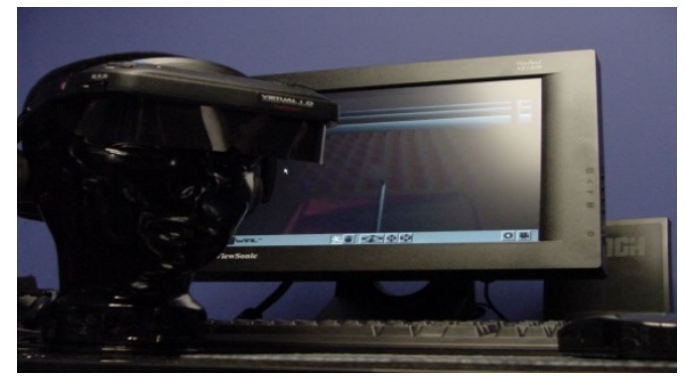

(a)

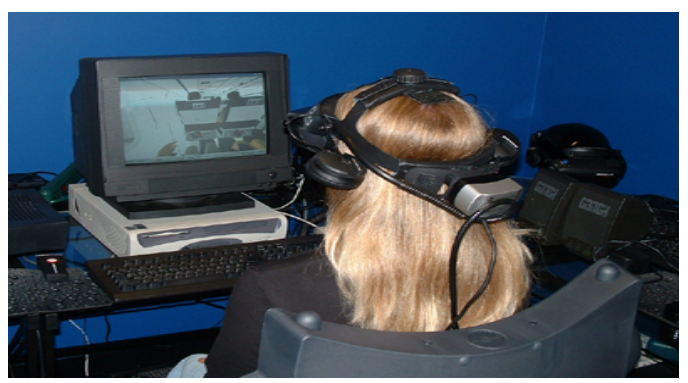

(b)

Figure 1. Depicts (a) A Traditional Virtual Reality Environment system and (b) A participant wearing a head-mounted display and head-tracking device immersed in the Traditional Virtual Reality Environment.

\subsection{Immersive Visualization Environment Experiment (IVE)}

Apparatus: The device used for this part of the experiment was the Immersive Visualization Environment (Spherical-based virtual environment), also known as a dome-shaped system (see Figures 2 and 3). This state-of-the-art equipment enhances the immersive virtual environment imaging with its four digital projectors and a large cylindrical screen. The particular immersive system used for the experiment is a spatially immersive visualization and features four digital projectors, OmniFocus ${ }^{\mathrm{TM}}$ Series 500 wide angle single lens projection system, and an $8 \mathrm{ft}$ by $10 \mathrm{ft}$ cylindrical screen with multi-channel visual display, coupled with integrated hardware or software warp and blend technology (see Figure 3, a schematic configuration of the IVE system). Numerous variations of IVE are designed and implemented at research and training laboratories in prime industries, such as Boeing, BMW, Lockheed Martin, and in branches of the Department of Defense, Army, Air Force, Navy, National Security Agency, just to list a few. Such installations have a wide range of applications, such as architectural design, flight simulation, military simulation, scientific visualization, experiential marketing, and industrial simulation (Maxwell, Griffith \& Finkelstein, 2014). 


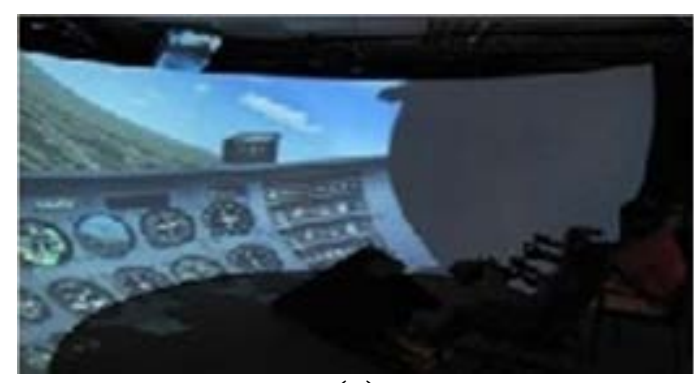

(a)

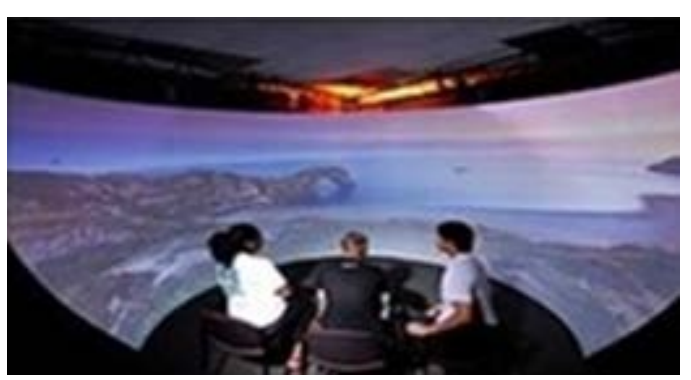

(b)

Figure 2. Illustrates (a) An airplane in the Immersive Visualization Environment system flying over terrain; and (b) Several subjects engaged in the Immersive Visualization Environment

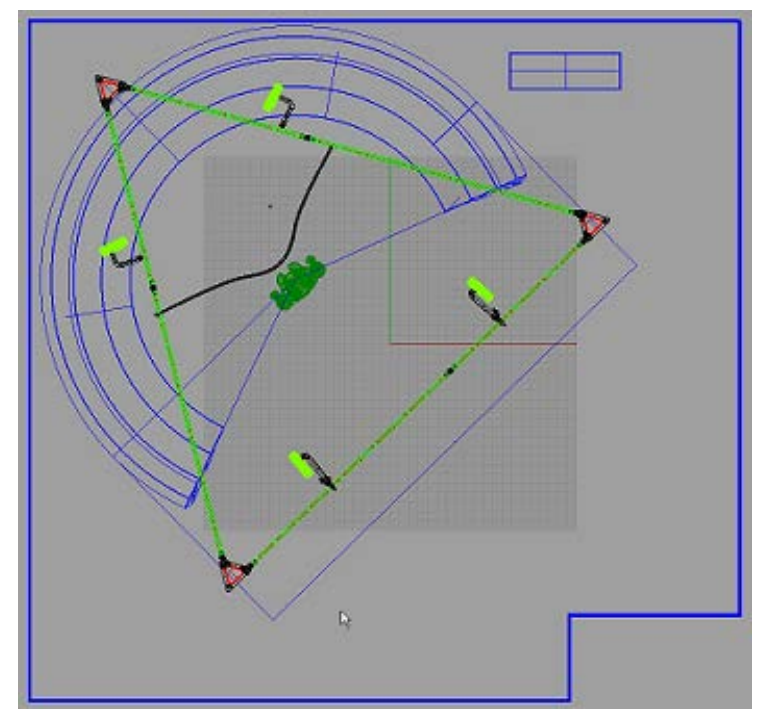

Figure 3. A schematic configuration of the Immersive Visualization Environment system

Procedure: Participants individually were seated in an aircraft-like seat placed a specific distance away from the screen, providing the individual with a fully immersed environment, and cancelling out any outer disturbances. Identical to the prior experiment, this seat had a vibration apparatus to correspond to the engine and flight turbulence. Although the environment was controlled, the participants had the ability to freely move their body parts without the restrictions of a helmet or hand held devices. The simulation used here was exactly the same as that used with the TVRE experiment. The participants could listen to sounds such as the flight attendant speaking, engine noises, and noises due to turbulence. It must be noted that the experiments were intentionally focused on visual and auditory stimuli, with limited interaction and use of directed manipulation by participants. Participants could view the virtual world by just moving their heads in the desired direction. Participants experienced thirty minutes in the airplane simulation and responded to the SMoP sense of presence questionnaire immediately afterward. The same definition of presence described in the prior experiment was given to participants of this experiment beforehand. Participants individually rated the questions quantitatively on a scale of 0 to 10 (Likert scale), with zero being equal to no sense of presence and ten being equal to complete immersion in the environment. There were no other rules imposed on how subjects could score their sense of presence.

\section{Results and Conclusions}

Data from the Subjective Measure of Presence (SMoP) instrument, a post-experience subjective measure of presence administered immediately after each simulation for both TVRE and IVE experiments, were collected and analyzed using appropriate statistical methods described below. 


\subsection{Data Analysis of Traditional Virtual Reality Environment - TVRE}

The questionnaire (SMoP) was administered immediately after the experiment in the TVRE. The SMoP consisted of 10 questions, of which only 2 were directly related to the hypothesis of this part of the study. Each question had 11-point Likert scale; participants would select a number between 0 and 10 indicating their level of sense of presence within the environment. The higher score indicates a higher sense of presence (with 0 being the lowest and 10 being the highest presence). Graphically, Figure 4 ( $a$ and b) illustrates the distribution of SMoP measures for rating the sense of presence in the real world while experiencing the virtual world in the TVRE (Q1), and for rating of the sense of presence in the virtual world during the experiment in the TVRE (Q2).

The mean ( $\mathrm{M}=6.42, \mathrm{SD}=2.25$ ) for Question-1 in the TVRE experiment was slightly higher than mean $(\mathrm{M}=6.29, \mathrm{SD}=2.16)$ for Question- 2 . However, a matched pair $\mathrm{t}$-test $(\mathrm{t}=0.56, \mathrm{df}=68$, $\mathrm{p}<0.05$ ) analysis applied to the scores given to both questions showed very strong evidence that there is no significant difference between the level of sense of presence of the real world while experiencing the virtual world when compared with sense of presencein the virtual world (see Table 1). This indicates that the reported sense of presence in the real world and virtual world were almost equally divided (approximately equal). Interestingly, the total means reported (total means of $12.71=$ Calculated mean of 6.42 for the real world scores+ mean of 6.29 for the virtual world scores) appear to be more than the expected 10 (expected 5 for the real world scores +5 for the virtual world scores). This finding will be described further in the comparison section of TVRE and IVE experiments.

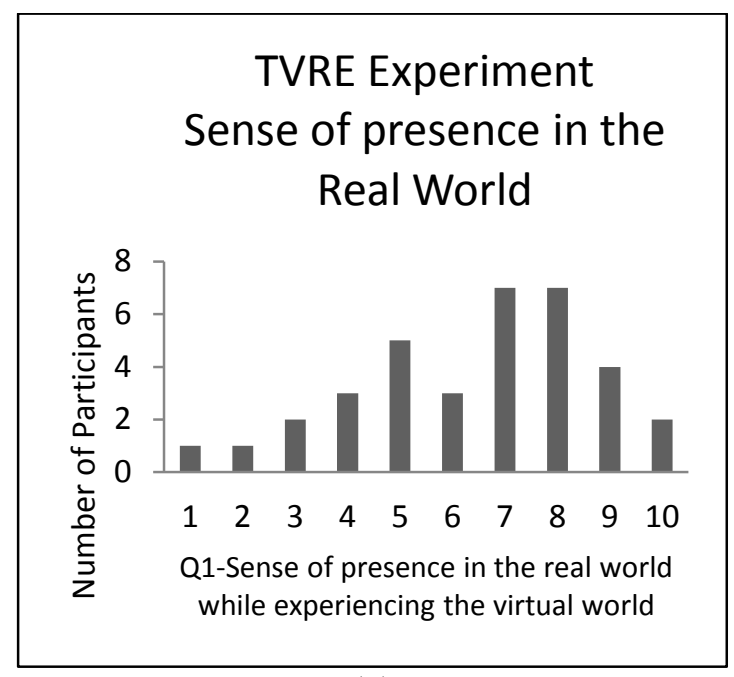

(a)

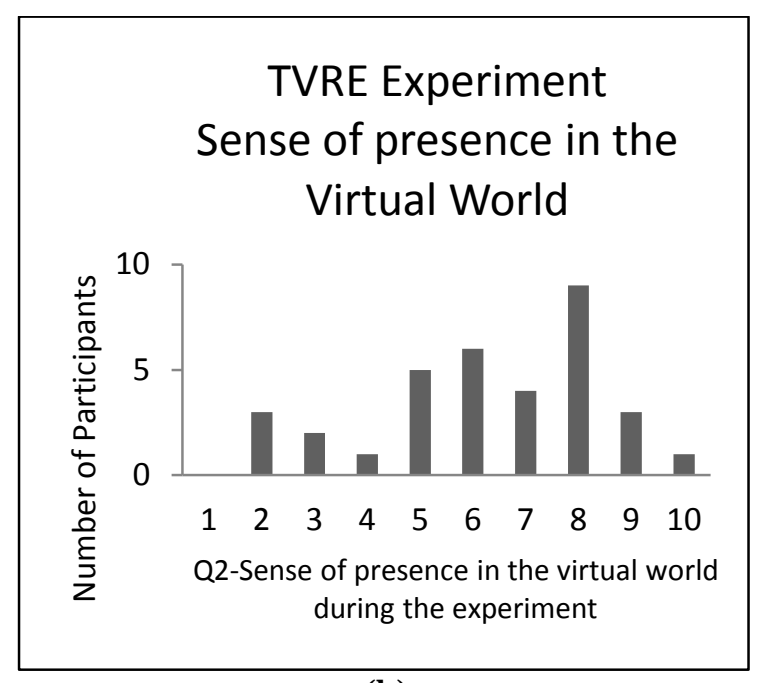

(b)

Figure 4. SMoP measures for (a) Rating of the sense of presence in the real world while experiencing the virtual world in the TVRE, and for (b) Rating of the sense of presence in the virtual world during the experiment in the TVRE. 


\begin{tabular}{|c|c|c|c|c|c|c|}
\hline & \multicolumn{6}{|c|}{ TVRE-Traditional Virtual Reality Environment } \\
\hline & \multirow{2}{*}{\multicolumn{2}{|c|}{$\begin{array}{l}\text { Q1- sense of presence in } \\
\text { the real world while } \\
\text { experiencing the virtual } \\
\text { world } \\
\text { (n=35) }\end{array}$}} & \multirow{2}{*}{\multicolumn{2}{|c|}{$\begin{array}{l}\text { Q2- sense of presence in } \\
\text { the virtual world during } \\
\text { the experiment } \\
\text { (n=35) }\end{array}$}} & \multicolumn{2}{|c|}{ Analysis } \\
\hline & & & & & & \\
\hline Measure & Mean & SD & Mean & SD & $\mathrm{t}$ & $\mathrm{p}$ \\
\hline SMoP $^{*}$ & 6.42 & 2.25 & 6.29 & 2.16 & 0.56 & $<0.05$ \\
\hline
\end{tabular}

*Subjective Measure of Presence

Table 1. Means and standard deviations of sense of presence scores (Q1 and Q2) for TVRE, and matched pair t-test analysis.

\subsection{Data Analysis of Immersive Visualization Environment - IVE}

For the IVE experiment, the same questionnaire (SMoP) was administered immediately after each session. Graphically, Figure 5 ( $a$ and $b$ ) exhibits the distribution of SMoP measures for (a) rating of the sense of presence in the real world while experiencing the virtual world in the IVE, and for (b) rating of the sense of presence in the virtual world during the experiment in the IVE.

The mean $(\mathrm{M}=5.01, \mathrm{SD}=1.66)$ for Question-1 of IVE was considerably lower than the mean $(\mathrm{M}=7.69, \mathrm{SD}=1.10)$ for Question-2. A matched pair $\mathrm{t}$-test $(\mathrm{t}=7.95, \mathrm{df}=68, \mathrm{p}<0.05)$ analysis applied to the scores given to both questions showed very strong evidence that there is a significant difference between the level of sense of presence of the real world while experiencing the virtual world and the sense of presence in the virtual world during the IVE experiment (see Table 2). This indicates that the reported sense of presence in the real world and virtual world were not equally distributed. Participants sensed a significantly higher sense of presence in the virtual world than in the real world during the experiment. Similar to the TVRE experiment, the total means (total means of $12.69=$ Calculated by mean of 7.69 for the real world scores + mean of 5.0 for the virtual world scores) appear to be more than the expected 10 (expected 5 for the real world +5 for the virtual world scores). This finding will be described further in the comparison section below.

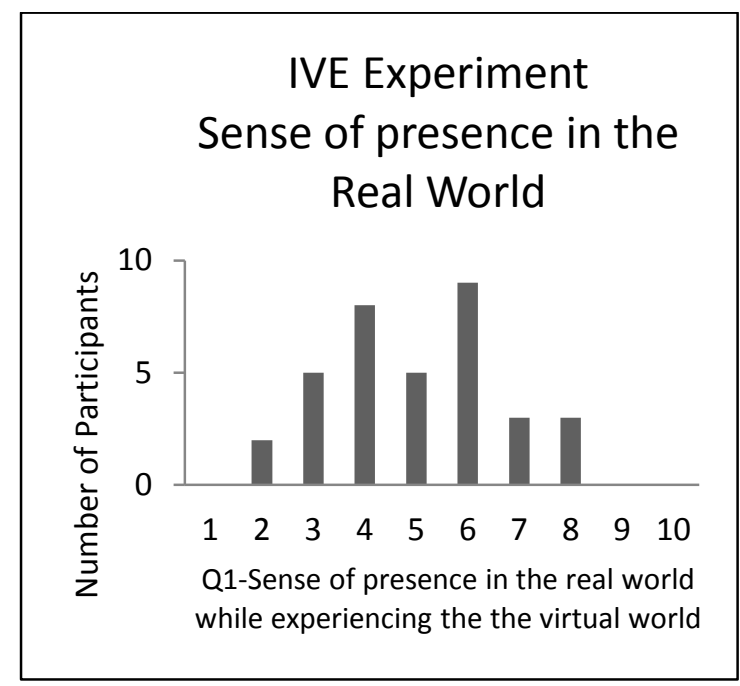

(a)

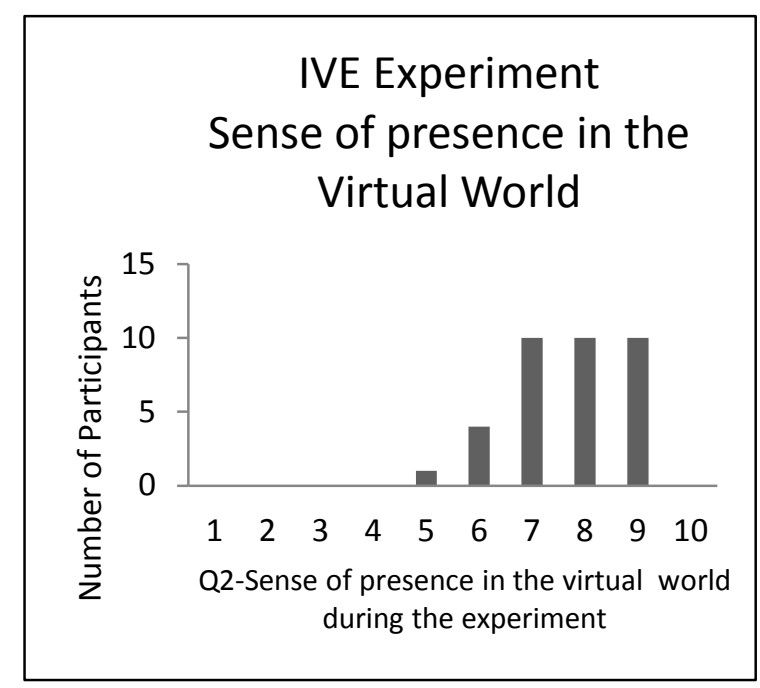

(b)

Figure 5. SMoP measures for (a) Rating of the sense of presence in the real world while experiencing the virtual world in the IVE, and for (b) Rating of the sense of presence in the virtual world during the experiment in the IVE. 


\begin{tabular}{|c|c|c|c|c|c|c|}
\hline & \multicolumn{6}{|c|}{ IVE-Immersive Visualization Environment } \\
\hline & \multirow{2}{*}{\multicolumn{2}{|c|}{$\begin{array}{l}\text { Q1- sense of presence } \\
\text { in the real world } \\
\text { while experiencing } \\
\text { the virtual world } \\
\quad(\mathrm{n}=35)\end{array}$}} & \multirow{2}{*}{\multicolumn{2}{|c|}{$\begin{array}{l}\text { Q2- sense of presence } \\
\text { in the virtual world } \\
\text { during the } \\
\text { experiment } \\
(\mathrm{n}=35)\end{array}$}} & \multicolumn{2}{|c|}{ Analysis } \\
\hline & & & & & & \\
\hline Measure & Mean & SD & Mean & SD & $\mathrm{t}$ & $\mathrm{p}$ \\
\hline SMoP* & 5.01 & 1.66 & 7.69 & 1.10 & 7.95 & $<0.05$ \\
\hline
\end{tabular}

Table 2. Means and standard deviations of sense of presence scores (Q1 and Q2) for IVE, and matched pair t-test analysis.

\subsection{Comparison of TVRE and IVE Experiments}

Table 3 shows the results of SMoP measurements for Question- 1 and for Question-2 of the TVRE and IVE experiments. In addition, this table illustrates the analysis of a comparison between each set of scores. A matched pair t-test $(\mathrm{t}=3.6 \mathrm{o}, \mathrm{df}=68, \mathrm{p} \leq 0.05)$ provided strong evidence that there was a significant difference between the means of TVRE and IVE scores for Question-1, indicating that the sense of presence in the real world while experiencing the IVE was lower than in the TVRE experiment. For Question-2 scores of both experiments, a matched pair $\mathrm{t}$-test $(\mathrm{t}=2.16, \mathrm{p} \leq 0.05)$ provided strong evidence that there was a significant difference between the means of TVRE and IVE scores, indicating that the sense of presence in the virtual world during the experiment of the IVE was higher than in the TVRE experiment. Based on these results, it is reasonable to state that the participants were much more immersed in the virtual world while using the IVE environment.

\begin{tabular}{|c|c|c|c|c|c|c|c|c|c|c|c|c|}
\hline & \multicolumn{12}{|c|}{$\begin{array}{c}\text { Comparison of TVRE-Traditional Virtual Reality Environment and } \\
\text { IVE-Immersive Visualization Environment }\end{array}$} \\
\hline & \multicolumn{4}{|c|}{$\begin{array}{l}\text { Q1- sense of presence in the } \\
\text { real world while experiencing } \\
\text { the virtual world }\end{array}$} & \multirow{2}{*}{\multicolumn{2}{|c|}{ Analysis }} & \multicolumn{4}{|c|}{$\begin{array}{l}\text { Q2- sense of presence in the } \\
\text { virtual world during the } \\
\text { experiment }\end{array}$} & \multirow{2}{*}{\multicolumn{2}{|c|}{ Analysis }} \\
\hline & \multirow{2}{*}{\multicolumn{2}{|c|}{$\begin{array}{c}\text { TVRE } \\
(\mathrm{n}=35)\end{array}$}} & \multirow{2}{*}{\multicolumn{2}{|c|}{$\begin{array}{c}\text { IVE } \\
(n=35)\end{array}$}} & & & \multirow{2}{*}{\multicolumn{2}{|c|}{$\begin{array}{c}\text { TVRE } \\
(\mathrm{n}=35)\end{array}$}} & \multirow{2}{*}{\multicolumn{2}{|c|}{$\frac{\text { IVE }}{(n=35)}$}} & & \\
\hline & & & & & \multicolumn{2}{|c|}{$(\mathrm{df}=68)$} & & & & & \multicolumn{2}{|c|}{$(\mathrm{df}=68)$} \\
\hline Measure & Mean & SD & Mean & $\mathrm{SD}$ & $\mathrm{t}$ & $\mathrm{p}$ & Mean & SD & Mean & SD & $\mathrm{t}$ & $\mathrm{p}$ \\
\hline SMoP* & 6.42 & 2.25 & 5.01 & 1.66 & 3.60 & $\leq 0.05$ & 6.29 & 2.16 & 7.69 & 1.10 & 2.16 & $\leq 0.05$ \\
\hline
\end{tabular}

*Subjective Measure of Presence

Table 3. Comparison of TVRE-Traditional Virtual Reality Environment and IVE-Immersive Visualization Environment

An interesting finding of this study is that data analysis indicated the total sense of presence scores for the virtual and real worlds in both experiments exceeded 100\% (Mean of TRVE of real world scores + Mean of TRVE of virtual world scores, that is 12.71; Mean of IVE of real world scores + Mean of IVE of virtual world scores, that is 12.70) for both TRVE and IVE experiments (see Figure 6). While commonsense would indicate that participants' total sense of presence in concurrent environments should not exceed $100 \%$, or 10 on the rating scale in this study, the analysis of data indicated this value was approximately $120 \%$ for both experiments. These results could have many implications, all of which would need to be independently studied in the future research endeavors. 


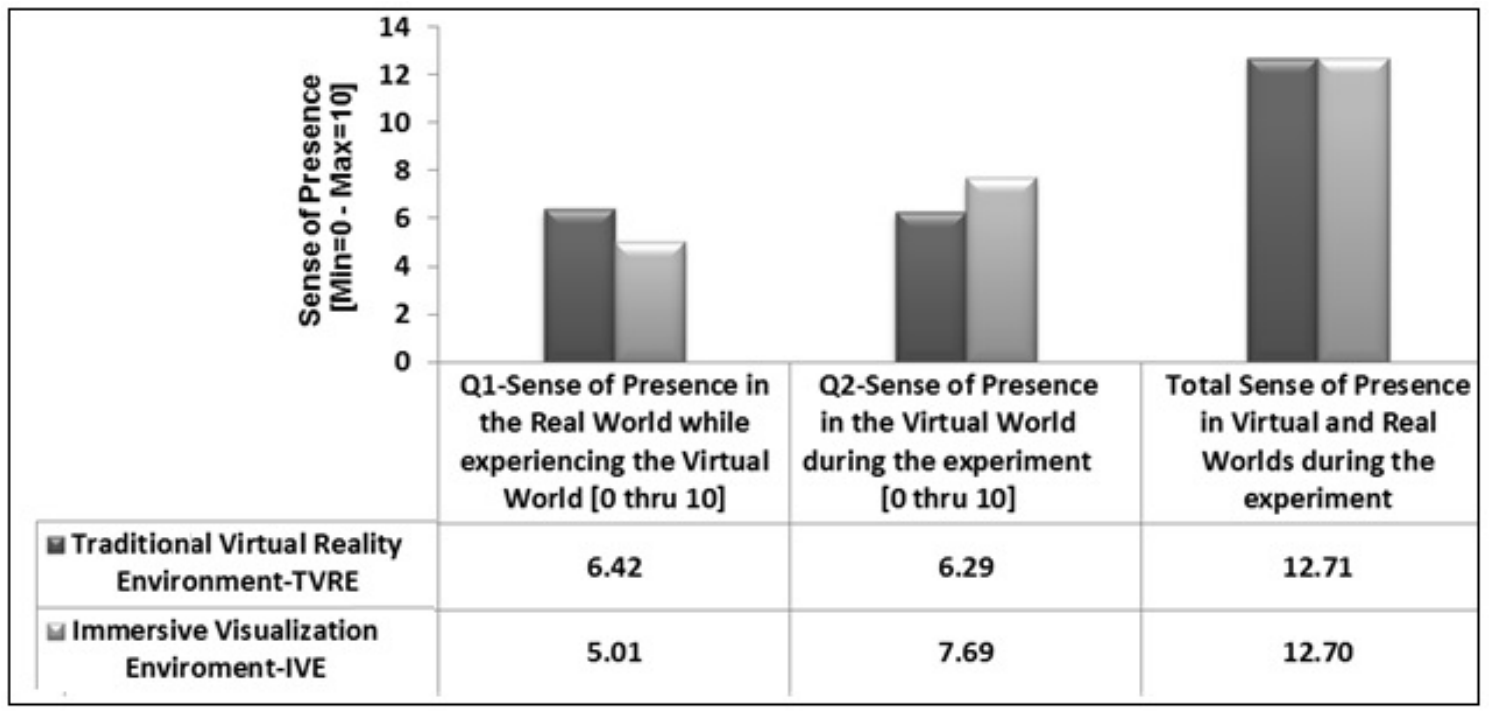

Figure 6. This graph shows the sense of presence in the real world while experiencing the virtual world, sense of presence in the virtual world during the experiment, and total sense of presence in both real and virtual worlds during experiments using the TVRE and IVE.

\section{Concise Discussions, Implications, and Extended Concluding Inferences}

Two experiments, one using a TRVE and one using an IVE were designed, developed and implemented to investigate the sense of presence and to determine which environment would induce a higher sense of presence in the virtual world. To the best of our knowledge, this is the first study in which these two specific environments were compared for the sense of presence they induce. The analysis of collected data supported the hypothesis of this study: participants were more immersed in the virtual world while using the IVE comparing with the TVRE.

As a general interpretation, it was also noted that the IVE group indicated a smaller SD's than the TVRE (please see Table 3). This signifies less variance within IVE group, which may have enhanced the response consensus for IVE compared to TVRE. The idea of response consensus coming out of SD might be connected to "focus" of response, making the implications proposed from IVE stronger.

Furthermore, the data analysis indicated that participants' total sense of presence in concurrent environments, either TVRE or IVE, exceeded 100\% (10 on the rating scale in this study). This study has some limitations. First, the number of participants was limited to seventy, and they were only from college student population. Second, the sense of presence was measured only by subjective self-reported measure using a limited number of questions from questionnaires. Third, although the measurement questionnaires used in this study were validated and repeatedly tested in many other experiments, physiological measurements could certainly be useful supplements to further study the sense of presence.

These findings of this study raise several possibilities for future research endeavors. For instance, research to determine why participants' overall ratings of sense of presence varies so widely, why the total subjective degree of sense of presence in both environments is higher than $100 \%$, or the make-up of individual factors within participants' reported sense of presence.

As clearly stated in the preceding experiments in this article, a limited, direct manipulation intentionally was incorporated, in order to keep the investigation focused on the effect of manageable visual and auditory stimuli on the participants' sense of presence. However, the researchers will be gradually introducing an increasing variety of direct manipulation within 
the future studies. As a consequence, the questionnaire will be extended accordingly, and the scope of the studies will be broadened.

While research in this particular field shows that subjective measurements positively correlate with objective measurement, physiological measurements-such as Eye-Tracking and EEG (electroencephalogram - noninvasive monitoring method to record electrical activity of the brain) - will be utilized during all stages of the future experiments. Specifically, in addition to subjective data, physiological data from each session will be collected and used for evaluation purposes. For example, eye tracking will be used to evaluate the level of attention allocated to areas of interest, and EEG will be used to evaluate whether cognitive problem states occurred less frequently.

As an example of the implications of this technology being investigated by the authors, the following learning aspect is briefly described: There is a growing gap between the pace of technical and scientific innovation and the speed with which humans can learn new concepts and knowledge. While the former is accelerating, the latter has thus far remained fairly constant (Mikropoulos \&Natsisl, 2011; Gilbert, 2001). Consequently, this gap is more apparent with the younger generations of learners. New and stimulating innovative educational techniques, concepts and materials will have to be developed to address this imbalance. The direction of the research described in this article not only will improve user experiences, but ultimately has the potential to drastically improve the efficiency and effectiveness of innovative technologies used in a broad range of training environments and fields.

Clearly, an immersive environment is becoming an increasingly important factor to users interacting with any application. Various kinds of displays for immersive environments have been developed, from small ( 720 x 480 Head-Mounted Display that create the perception of a large screen) to the large displays such as IMAX, to induce an immersive feeling in viewers. Furthermore, with the recent demand for "real-feeling" media, we see a newmarket for various types of displays being formed (e.g., new technology like Google Glass - an optical headmounted display that induces an immersive experience for users). All immersive virtual environment systems-small or large, simple or complex - can take advantage of improved interface design to advance a more natural user experience. Further investigation into the sense of presence will need to be conducted in order to better understand this phenomenon. Research of this kind enhances opportunities for the discovery and generation of new knowledge and theories, which in turn advances the efficiency and effectiveness of humancomputer interaction.

\section{Acknowledgment}

This effort was supported by an equipment grant from the U.S. Army Research Office (ARO) and assistance from PSLSAMP program (State-wide grant by NSF-National Science Foundation). The content of this work does not reflect the position or policy of the ARO or NSF and no official endorsement should be inferred. We sincerely thank the editor, Kathy Lynch, and reviewers for their professional reviews and constructive suggestions.

\section{References}

Arino, J . J ., Juan, M. C., Gil-Gomez, J . A. \& Molla, R. (2014). A Comparative Study Using Autostereoscopic Display with Augmented and Virtual Reality, Behaviour \&Information Technology, 33 (6), 646-655.

Barfield, W., Sheridan, T.B., Zeltzer, D., \&Slater, M. (1995). Presence and Performance within Virtual Environments, In Virtual Environments and Advanced Interface Design, Barfield, W. \&Furness (Eds.), London: Oxford University Press.

Bouchard, S., Cote, S., St-J acques, J., Robillard, G. \& Renaud, P. (2006). Effectiveness of virtual reality exposure in the treatment of arachnophobia using 3D games, Technol Health Care, 14(1), 19-27. 
Chertoff, D. \& Schatz, S. (2014). Beyond Presence: How Holistic Experience Drives Training and Education. In Handbook of Virtual Environments (pp. 959-1000), Hale, K.S. \& Stanney, K.M. (Eds.), Boca Raton: CRC Press-Taylor \&Francis.

Coelho, C., Tichon, J., Hine, T., Wallis, G. \& Riva, G. (2006). Media Presence and Inner Presence: The Sense of Presence in Virtual Technologies, In From Communication to Presence: Cognition, Emotions and Culture toward the Ultimate Communicative Experience, Riva, G., Anquera, M.T., Wiederhold, B.K. \& Mantovani, F. (Eds.), 2-5.

De Leo, G., Diggs, L.A., Radici, E. \& Mastaglio, T.W. (2014). Measuring Sense of Presence and User Characteristics to Predict Effective Training in an Online Simulated Virtual Environment. Simulation in Healthcare, The J ournal of the Society for Simulation in Healthcare, 9(1), 1- 6

Dillon, C., Keogh, E., Freeman, J. \& Davidoff, J . (2001). Presence: Is Your Heart in It? Proceedings of the 4th Annual International Workshop on Presence, Philadelphia, USA.

Fontaine, G. (1992). The Experience of Sense of Presence in Intercultural and International Encounters, Presence: Teleoperators and Virtual Environments. 1(4), 482-489.

Gilbert, S.W. (2001). No Moore's Law for Learning, Syllabus - Technology Implementation, 14 (8), 28.

Gruchalla, K. (2004). Immersive Well-Path Editing: Investigating the Added Value of Immersion. IEEE Virtual Reality, 157-164.

Hendrix, C. \& Barfield, W. (1995). Presence in virtual environments as a function of visual and auditory cues, VRAIS '95 Proceedings of the Virtual Reality Annual International Symposium, 74-79.

Hodges, L.F., Rothbaum, B.O., Alarcon, R., Ready, D., Shahar, F., Graap, K., Pair, J ., Herbert, P., Gotz, D., Wills, D. \& Baltzell., D. (1999). Virtual Vietnam: a Virtual Environment for the Treatment of Vietnam War Veterans with Post-traumatic Stress Disorder, Cyber Psychology \& Behavior 2(1).

Hoffman, H.G., Patterson, D.R. \& Carrougher, G. (2000). Use of Virtual Reality for Adjunctive Treatment of Adult Burn Pain During Physical Therapy: A Controlled Study, Clinical J ournal of Pain, 16(3), 244-250.

Ijsselsteijn,W.A., Ridder, H., Freeman, J. \& Avons, S.E. (2002). Presence: Concept, Determinants, And Measurement, Proceedings of SPIE 3959, Human Vision and Electronic Imaging, 520.

J uan, M. C., Banos, R., Botella, C., Perez, D., Alcaniz, M. \& Monserrat, C. (2006). An Augmented Reality System for Acrophobia: The Sense of Presence Using Immersive Photography, Presence: Teleoperators and virtual environments, 15(4), 393-402.

J uan, M. C. \& Calatrava, J . (2011). An Augmented Reality System for the Treatment of Phobia to Small Animals Viewed via an Optical See-through HMD, Comparison with a Similar System Viewed via a Video See-through, International J ournal of Human-Computer Interaction, 27(5), 436-449.

Juan, M. C. \& Perez, D. (2009). Comparison of the Levels of Presence and Anxiety in an Acrophobic Environment Viewed via HMD or CAVE, Presence: Teleoperators and virtual environments, 18(3), 232-248.

J urnet, A. \& Maldonado, J . (2010). Influence of Personality and Individual Abilities on the Sense of Presence Experienced in Anxiety Triggering Virtual Environments, International J ournal of Human-Computer Studies, 68(10), 788-801.

Lee, C., Chou, C. \& Sun, T. (2015). Evaluating Presence for Customer Experience in a Virtual Environment: Using a Nuclear Power Plant as an Example, Human Factors and Ergonomics in Manufacturing \& Service Industries, 25(2), 484-499. 
Lin, J J .-W., Duh, H.B.L., Parker, D.E., Abi-Rached, H. \&Furness, T.A. (2002). Effects of Field of View on Presence, Enjoyment, Memory, and Simulator Sickness in a Virtual Environment, Proceedings of Virtual Reality, IEEE, 164-171.

Lombard, M. \& Ditton, T. (1997). At the heart of it all: The concept of presence, J ournal of Computer Mediated Communication, 3(2), 1-43.

Maxwell, D., Griffith, T. \& Finkelstein, N.M. (2014). Use of Virtual Worlds in the Military Services as Part of Blended Learning Strategy, In Handbook of Virtual Environments (pp. 959-1000), Hale, K.S. \& Stanney, K.M. (Eds.), Boca Raton: CRC Press-Taylor \& Francis.

Meehan, M., Insko, B., Whitton, M. \&Boorks, F.P. (2002). Physiological Measures of Presence in Stressful Virtual Environment, ACM Transaction on Graphics, 21(3), 645-652.

Mikropoulos, T.A. \&Natsisl, A. (2011). Educational Virtual Environments: A Ten-Year Review Of Empirical Research (1999- 2009), Computers \& Education, 56(3), 769- 780.

Munro, A., Patrey, J., Biddle, E.S. \& Carroll, M. (2014).Cognitive Aspects of Virtual Environment Design, In Handbook of Virtual Environments (pp. 391-410), Hale, K.S. \& Stanney, K.M. (Eds.), Boca Raton: CRC Press-Taylor \& Francis.

North, M.S. (2002). A Study of the Sense of Presence in Virtual Environment Experiment, CISST '02 International Conference, 623-626.

North, M. M., North, M. S. \& Coble, J . R., (1996a). Virtual Reality Therapy, an Innovative Paradigm, IPI Press.

North, M. M., North, S. M. \& Coble, J. R. (1996b). Application: Psychotherapy, Flight Fear Flees, CyberEdge J ournal, 6(1), 8-10.

Nunez, D. \& Blake, E. (2001). Cognitive Presence as a Unified Concept of Virtual Reality Effectiveness. Proceedings of the 1st International Conference on Computer graphics, Virtual Reality and Visualization, South Africa 115-118.

Optale, G., Munari, A., Nasta, A., Pianon, C., Verde, J . \& Viggiano, J . (1998). A VR Based Therapy for the Treatment Of Impotence and Premature Ejaculation, In Virtual Environments in Clinical Psychology and Neuroscience, Giuseppe Riva, Brenda K. Wiederhold and Enrico Molinari (Eds.), Amsterdam: IOS Press.

Palyo, S. A., Schopmeyer, K. A. \& McQuaid, J. R. (2012). Tele-pain management: Use of videoconferencing technology in the delivery of an integrated cognitive- behavioral and physical therapy group intervention, Psychological Services, 9(2), 200-202.

Pausch, R., Proffitt, D. \& Williams, G. (1997). Quantifying Immersion in Virtual Reality. Proceedings of SIGGRAPH 97, Computer Graphics, 13-18.

Psotka, J. \& Davison, S. (1993). Cognitive Factors Associated with Immersion in Virtual Environments. Proceedings of the Intelligent Computer-Aided Training and Virtual Environment Technology, Houston, TX.

Riva, G., Mantovani, F., Capideville, C.S., Preziosa, A., Morganti, F., Villani, D., Gaggioli, A., Botella, C. \& Alcaniz, M. (2007). Affective Interactions Using Virtual Reality: The Link between Presence and Emotions, Cyberpsychology \& Behavior, 10(1), 45-56.

Rizzo, A. S., Difede, J., Rothbaum, B.O., Reger, G., Spitalnick, J.S., Cukor, J., \& Mclay, R. (2010). Development and early evaluation of the Virtual Iraq/Afghanistan exposure therapy system for combat-related PTSD. Annals of the New York Academy of Science, 1208, 114-125.

Sanchez-Vives, M.V. \& Slater, M. (2005). From Presence to Consciousness through Virtual Reality, Nature Reviews Neuroscience, 6(4), 332- 339. 
Sheridan, T.B. (1996). Further Musings on the Psychophysics of Presence, Presence: Teleoperators and Virtual Environments, 5(2), 241-246.

Sheridan, T.B. (1999). Descartes, Heidegger, Gibson, and God Toward and Eclectic Ontology of Presence, Presence: Teleoperators and Virtual Environments, 8(5), 551-559.

Sheridan, T.B. (2000). Interaction, Imagination and Immersion: Some Research Needs, Proceedings of the ACM symposium on Virtual reality software and technology,1-7.

Shim, W. \&Kim, G. J . (2004). Designing for Presenceand Performance: The Case of the Virtual Fish Tank, Presence: Teleoperators and Virtual Environments, 12(4), 374-386.

Slater, M. (1999). Measuring Presence: A Response to the Witmer and Singer Presence Questionnaire, Presence: Teleoperators and Virtual Environments, 8(5), 560-565.

Slater, M. (2009). Place Illusion and Plausibility Can Lead to Realistic Behaviour in Immersive Virtual Environments, Philosophical Trans. Royal Soc. London, 364(1535), 3549- 3557.

Slater, M. (2002). Presence and the Sixth Sense, Presence: Teleoperators and Virtual Environments, 11(4), 435-439.

Slater, M., Usoh, M., \&Steed, A. (1994). Depth of Presence in Virtual Environments, Presence: Teleoperators and Virtual Environments, 3(2), 130-144.

Steuer, J . S. (1992). Defining Virtual Reality: Dimensions Determining Telepresence, J ournal of Communication, 4, 73-93.

Usoh, M., Arthur, K., Whitton, M., Bastos, R., Steed, A., Slater, M. \&Brooks, F. (1999).

Walking > Walking-in-Place > Flying, in Virtual Environments, Proceedings of the 26th Annual Conference on Computer Graphics and Interactive Techniques, 359-364.

Waterworth, J .A. \& Waterworth, E.L. (2003). Being and Time: J udged Presence and Duration as a Function of Media Form. Presence: Teleoperators and Virtual Environments, 12(5), 495-513.

Witmer, B.G. \& Singer M.J . (1998). Measuring Presence in Virtual Environments: A Presence Questionnaire, Presence: Teleoperators and Virtual Environments, 7(3), 225-250.

Yu, I., Mortensen, J ., Khanna, P., Spanlang, B. \& Slater, M. (2012). Visual Realism Enhances Realistic Response in an Immersive Virtual Environment, IEEE Computer Graphics \& Applications, 32(6), 36-45.

Zeltzer, D. (1992). Autonomy, Interaction and Presence, Presence: Teleoperators and Virtual Environments, 1(1), 109-112.

Copyright: ( $) 2016$ North \& North. This is an open-access article distributed under the terms of the Creative Commons Attribution-NonCommercial 3.0 Australia License, which permits non-commercial use, distribution, and reproduction in any medium, provided the original author and AJ IS are credited.

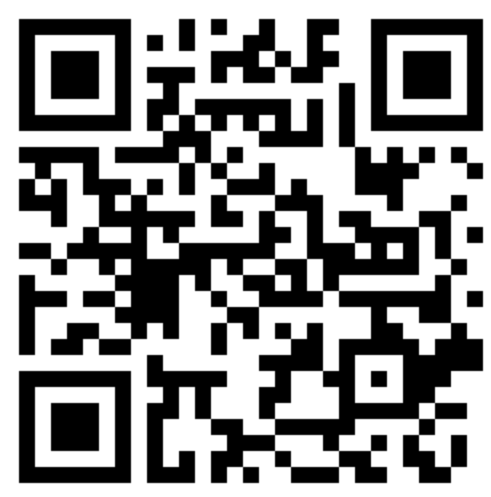

